\title{
The effect of mirabegron, used for overactive bladder treatment, on female sexual function: a prospective controlled study
}

\author{
A. Zachariou ${ }^{1,5^{*}}$ (D) C. Mamoulakis ${ }^{2}$, M. Filiponi ${ }^{3}$, F. Dimitriadis ${ }^{1}$, J. Giannakis ${ }^{1}$, S. Skouros ${ }^{1}$, P. Tsounapi ${ }^{4}$, \\ A. Takenaka ${ }^{4}$ and N. Sofikitis ${ }^{1}$
}

\begin{abstract}
Background: Aim of the study was to determine the effect of mirabegron, used for overactive bladder (OAB) treatment, on female sexual function.

Methods: Eighty five sexually active women suffering from overactive bladder were prospectively enrolled in this study. Females were divided into two groups. In Group A (control), 48 patients received no treatment and in Group B, 37 patients received mirabegron $50 \mathrm{mg} /$ daily for 3 months. Patients were evaluated with FSFI-Gr at the beginning of the study and again after a period of 3 months.

Results: In Group B, there was a significant increase post-treatment compared to baseline $(p<0.001)$ in total FSFI (20.3 (3. 8) to 26.6 (4.2)) and all domains (desire: 3.0 (1.2) to 4.8 (1.2)), arousal: 3.0 (0.8) to 4.8 (0.9), lubrication: 3.9 (1.1) to 4.8 (1.2), orgasm: 3.6 (0.8) to $4.8(1.0)$, satisfaction: $3.2(0.4)$ to $4.0(0.8)$ and pain: $3.2(0.8)$ to $4.4(1.2))$. In Group A, there were no statistically significant changes in pre- and post-observation values.
\end{abstract}

Conclusions: This study is one of the few demonstrating that management of OAB with mirabegron improves female sexual function.

Trial registration: TRN ISRCTN17199301, 20/10/2017, retrospectively registered.

Keywords: Female sexual dysfunction, Mirabegron, Overactive bladder

\section{Background}

Overactive bladder $(\mathrm{OAB})$ is defined by the International Continence Society (ICS) as urinary urgency in the absence of any known infection or other obvious pathology. $\mathrm{OAB}$ is usually characterized by frequency and nocturia, but may or may not cause urinary incontinence [1]. It has been shown to affect up to $36 \%$ of adult women in Europe and US [2,3].

Although not life threatening, $\mathrm{OAB}$ is a debilitating disease which can substantially impede the quality of life,

\footnotetext{
* Correspondence: zahariou@otenet.gr

Presented at the $19^{\text {th }}$ Congress of the European Society of Sexual Medicine 2017 in Nice, France, February 1-3, 2017

${ }^{1}$ Department of Urology, School of Medicine, loannina University, loannina, Greece

53 Spyridi Street, 38221 Volos, Greece

Full list of author information is available at the end of the article
}

resulting in low self-esteem, anxiety, depression, impairment of work productivity and increase in the number of falls and fractures [4]. Women with $\mathrm{OAB}$ experience increased incidence of sexual problems, sometimes with consequent personal distress and sexual partner compatibility issues. [5]. The impact of OAB symptoms on sexual function in women has been evaluated in a few studies [6-9]. Patel et al. [6] reported that $25 \%$ of their female $O A B$ population had some degree of sexual dysfunction, meaning that $\mathrm{OAB}$ has a greater effect on female sexual health than it does urinary incontinence.

Female sexual dysfunction (FSD) is traditionally classified into disorders of desire, arousal, lubrication, orgasm and pain. In the absence of detailed epidemiological data, current estimates have up to $43 \%$ of women complaining of at least one sexual issue [10]. Women are at 
risk of developing FSD due to physiologic, iatrogenic and psychological factors. Lower tract urinary tract infections are a further, independent FSD cause [10, 11]. To identify FSD, appropriate assessment guidelines should be applied. So as to ascertain sexual history and enable assessment, there are a number of self-reporting questionnaires available. The Female Sexual Function Index (FSFI) is a concise, multidimensional "gold standard" tool which is regarded in high-esteem [12].

Recently introduced as an oral treatment for $\mathrm{OAB}$, mirabegron (a $\beta 3$-adrenergic agonist compound) improves storage capacity of bladder without inducing anticholinergic adverse events [13]. In four, large-scale 12-week phase III studies [14-17], a pooled analysis [18] and 12-month study [19], mirabegron consistently demonstrated superiority over placebo with respect to reductions in incontinence episodes and micturition frequency, with a similar incidence of adverse effects as the placebo.

The objective of the current study is to evaluate the effect of the $\beta 3$-adrenoceptor agonist, mirabegron, as used for $O A B$ treatment on the sexual function of women (employing FSFI-Gr, a validated questionnaire translated into the Greek language).

\section{Methods}

Between January 2016 and December 2016, 85 sexually active women with confirmed $\mathrm{OAB}$, had referred to the Urogynecology outpatient clinic and were prospectively enrolled in this study. OAB was determined using the International Continence Society definition [1]. The urination frequency of all women was 8 or more times a day, with urge symptoms independent of incontinence. $O A B$ was present in all women for a minimum of 3 months and none of the women had undergone prior treatment for the condition. Other inclusion criteria were the willing of women to comply with the protocol and the capability to complete the voiding diaries and the questionnaires without assistance.

Subjects were excluded from inclusion if they had clinically significant stress urinary incontinence, neurogenic bladder and urinary retention or were at risk of these conditions. Women with a history of pelvic muscle training programs were excluded because it is accepted that pelvic floor muscle exercises improve female sexual function [20]. The protocol for the research project was approved by ELPIS HOSPITAL Ethics Committee and informed consent was taken from all the women.

The inclusion criteria also integrated women over the age of 18 being in a sexually active relationship. Women who stated that they were not sexually active were asked to indicate the reason and were excluded from further analysis. Women who considered that there was no need for long-term treatment for $\mathrm{OAB}$ or were afraid of regimen's adverse effects were included in control group.

Patients were assessed using a comprehensive history, a detailed general and neurological physical examination, as well FSFI. According to the latest report of the International Consultation on Sexual Medicine, the FSFI remains the "gold standard" assessment tool, has a level of evidence 1 and recommendation grade $\mathrm{A}$, for evaluating female sexual dysfunction [21]. Item selection and categories were based on the American Foundation for Urological Diseases classification system of female sexual dysfunction. Furthermore, FSFI has been translated and validated in the Greek language [22]. All women were asked to complete the Greek version of the FSFI, which evaluates the four phases of female sexual function and categorizes sexual dysfunction in the domains of (a) desire (b) arousal (c) lubrication (d) orgasm (e) satisfaction and (f) pain. The development of a scoring system, whereby higher scores indicate a healthier condition allowed the attainment of individual domain scores. Wiegel et al. [23] found that a total FSFI score of 26.5 is the optimal cut-off score for differentiating women with and without sexual dysfunction. We used the same cut-off scores in order to have comparable results with matching papers.

To determine the eligible women all females were asked to answer the question: "Do you have sexual distress associated with sexual dysfunction?" and only women who gave a negative answer were finally recruited for analysis, since sexual distress needs special questionnaires to be evaluated. Patients were divided into two groups. Group A, which is defined as a control group, consisted of 48 women. None of these females with $\mathrm{OAB}$ wished to receive any therapy. On the other hand, in Group B, 37 patients with OAB were treated with mirabegron $50 \mathrm{mg}$ daily for 3 months.

Patients of Group A (without OAB therapy) completed a 3 day micturition diary prior to and after 3 month-observation-period. Patients of Group B completed a 3 day micturition diary prior to and immediately after the third month of mirabegron treatment. For each episode of urinary symptoms, the patient recorded the date and time, regardless of the presence of urgency and/or incontinence, the volume voided and the influence of the episode (of urinary symptoms) on the patient's sleep. All women within Group B attended monthly office visits to ensure patients' compliance with the treatment. In Group A, all women attended monthly office visits to ensure that they did not have any pharmacotherapy or behavioral therapy for OAB. Within Group A and Group B, voiding frequency, nocturia, urgency episodes, incontinent episodes, number of incontinence pads used, and voided volume were measured post-treatment using the 3 day micturition diary. All 
patients completed the FSFI questionnaire at the beginning and after the completion of the 3 month study.

All outcome variables were tested for normality using the Shapiro-Wilk W test. Concretely, the following continues/ordinal variables were tested per group: age, body weight, symptom duration, parity; pre- and post-observation/treatment FSFI domains (desire, arousal, lubrication, orgasm, satisfaction, pain), total score of sexual function and percentage (\%) improvement in total score of sexual function; pre- and post-observation/treatment episodes of frequency, urgency, nocturia, incontinence; number of pads needed; and voided volumes. The potential presence of any correlation was investigated between the \% of improvement in LUTS/incontinence and in sexual function (separately for each parameter) in order to evaluate the effect of $\mathrm{OAB}$ improvement on sexual function. Finally, \% improvement in total score of sexual function was compared between groups and a multivariate linear regression analysis was performed in order to investigate the effect of several independent parameters on sexual function. The \% improvement in total score of sexual function was used as dependent variable. The \% improvements in frequency, urgency, nocturia, incontinence episodes, number of pads needed and voided volume were considered as independent variables. Data were analyzed using IBM Corp. Released 2016. IBM SPSS Statistics for Windows, Version 24.0. Armonk, NY: IBM Corp. Two-tailed $p<0.050$ was considered significant.

\section{Results}

All tested variables showed significant departures from the normal distribution. The only exceptions were the pre- and post-observation/treatment total scores of sexual function and the voided volumes. Consequently, non-parametric tests (Mann Whitney U test and Wilcoxon signed-rank test, respectively) were performed for all comparisons (for uniformity purposes) between and within groups, respectively; all data are presented as medians (interquartile ranges; IQRs).

Among the 48 women who reported sexual activity in the last 4 weeks from Group A, 11 women reported during the monthly visits that they had decided to follow pharmacotherapy/behavioral therapy for $\mathrm{OAB}$ and were therefore excluded from the study. Furthermore, 2 women from Group A and 2 women from Group B refused to complete the FSFI questionnaire at the end of 3 month period and were also excluded. There were no adverse reactions from mirabegron administration during the study.

Demographic characteristics and baseline $\mathrm{OAB} /$ sexual scores did not differ significantly between groups (Table 1). Sixty-five percent of patients in Group B who were incontinent at baseline became continent by the study-endpoint. Furthermore, all urinary outcomes, all
Table 1 Demographic characteristics and baseline OAB/sexual scores of participants

\begin{tabular}{llll}
\hline Variable & Group A & Group B & $P$ value \\
\hline Age (yr) & $43.5(10.0)$ & $43(10)$ & 0.838 \\
Body weight $(\mathrm{kg})$ & $59.0(14.0)$ & $55.0(14.0)$ & 0.406 \\
Symptom duration $(\mathrm{yr})$ & $4.2(1.5)$ & $4.2(3.3)$ & 0.821 \\
Parity & $2.0(2.0)$ & $2.0(1.0)$ & 0.738 \\
Frequency & $11.0(1.0)$ & $11.0(2.0)$ & 0.213 \\
Urgency episodes & $6.5(1.0)$ & $7.0(2.0)$ & 0.303 \\
Nocturia episodes & $2.0(1.0)$ & $2.0(1.0)$ & 0.227 \\
Incontinence episodes & $2.0(1.0)$ & $2.0(1.0)$ & 0.287 \\
Incontinence pads & $5.0(2.0)$ & $4.0(2.0)$ & 0.838 \\
Voided volume (ml) & $121.5(31.0)$ & $117.0(33.0)$ & 0.725 \\
Desire & $3.0(0.6)$ & $3.0(1.2)$ & 0.411 \\
Arousal & $3.6(0.6)$ & $3.0(0.8)$ & 0.281 \\
Lubrication & $3.6(0.9)$ & $3.9(1.1)$ & 0.214 \\
Orgasm & $3.6(0.4)$ & $3.6(0.8)$ & 0.253 \\
Satisfaction & $3.2(0.4)$ & $3.2(0.8)$ & 0.099 \\
Pain & $3.2(0.4)$ & $3.2(0.8)$ & 0.068 \\
Total Score of Sexual Function & $20.0(2.5)$ & $20.3(3.8)$ & 0.355 \\
\hline
\end{tabular}

FSFI domain scores and the total score of sexual function improved significantly in Group B at 3 months, in contrast to Group A (Tables 2, 3 and 4). Spearman's rank-order correlation test yielded statistically significant (negative) correlations between \% improvement in LUTS/incontinence and \% improvement in sexual function were detected exclusively in Group B (frequency-lubrication, nocturia-arousal, incontinence-sexual satisfaction; Table 5).

Total score of sexual function improvement (\%) differed significantly between groups (Group A vs. Group

Table 2 Urinary evaluation of the participants

\begin{tabular}{llll}
\hline Group A & Pre-observation & Post-observation & $P$ value \\
Frequency & $11.0(1.0)$ & $11.0(1.0)$ & 0.200 \\
Urgency episodes & $6.5(1.0)$ & $7.0(1.0)$ & 0.093 \\
Nocturia episodes & $2.0(1.0)$ & $1.0(1.0)$ & 0.231 \\
Incontinence episodes & $2.0(1.0)$ & $2.0(2.0)$ & 0.332 \\
Incontinence pads & $5.0(2.0)$ & $5.0(2.0)$ & 0.231 \\
Voided volume (ml) & $121.5(31.0)$ & $114.5(27.0)$ & 0.001 \\
Group B & Pre-treatment & Post-treatment & $P$ value \\
Frequency & $11.0(2.0)$ & $9.0(2.0)$ & $<0.001$ \\
Urgency episodes & $7.0(2.0)$ & $4.0(2.0)$ & $<0.001$ \\
Nocturia & $2.0(1.0)$ & $1.0(1.0)$ & $<0.001$ \\
Incontinence episodes & $2.0(1.0)$ & $1.0(1.0)$ & $<0.001$ \\
Incontinence pads & $4.0(2.0)$ & $2.0(2.0)$ & $<0.001$ \\
Voided volume $(\mathrm{ml})$ & $117.0(33.0)$ & $148.0(26.0)$ & $<0.001$ \\
\hline
\end{tabular}


Table 3 Comparison of pre-observation and post-observation FSFI in Group A

\begin{tabular}{llll}
\hline & Pre-observation & Post-observation & $P$ value \\
\hline Desire & $3.0(0.6)$ & $3.0(0.6)$ & 0.524 \\
Arousal & $3.6(0.6)$ & $3.6(0.6)$ & 0.628 \\
Lubrication & $3.6(0.9)$ & $3.9(0.6)$ & 0.713 \\
Orgasm & $3.6(0.4)$ & $3.6(0.4)$ & 0.505 \\
Satisfaction & $3.2(0.4)$ & $2.8(0.4)$ & 0.109 \\
Pain & $3.2(0.4)$ & $3.2(0.8)$ & 0.424 \\
Total Score of Sexual Function & $20.0(2.5)$ & $19.8(2.0)$ & 0.609 \\
\hline
\end{tabular}

B: 1.0 (3.7) vs. 32.6 (7.9); $p<0.001)$. Multivariate linear regression analysis run to predict \% improvement in total score of sexual function from group, as well as \% improvements in frequency, urgency, nocturia, incontinence episodes, number of pads needed and voided volume revealed that Group and \% improvements in frequency statistically significantly predicted \% improvement in total score of sexual function, $\mathrm{F}(7,77)=141.970$, $p<.001, \mathrm{R}^{2}=0.928$. All seven variables added statistically significantly to the prediction, $p<0.001$. The multivariate linear regression model is presented in Table 6.

\section{Discussion}

This study is one of the few, to our knowledge, to demonstrate the effect of mirabegron, the first $\beta-3$ adrenoceptor agonist, on sexual function of women suffering from OAB. Our data has indicated that after 3 months evaluation, females with $\mathrm{OAB}$ receiving mirabegron $50 \mathrm{mg}$ revealed statistically significant changes in FSFI total score and all subscales.

$\mathrm{OAB}$ symptoms, urinary incontinence and sexual health in general are topics many find difficult to discuss. Not only may stigma make sufferers reluctant to approach a health professional, but it may also make health professionals embarrassed to confront patients. Self-reporting rather than interview-administered questionnaires greatly reduce this barrier. As FSFI allows a quantitative evaluation and can be used to study sexuality changes after therapeutic intervention, it has a distinct advantage over other assessment tools like diaries or calendars [24]. This tool is a reliable self-reporting measure of FSD which only requires 15 min to complete. Although it excludes issues involving personal stress, it measures outcomes of therapeutic response by design.

Female sexual dysfunctions can interfere with intimacy, affect a marital relationship and ultimately erode well-being and overall health. Although sexual dysfunction is more likely in women than men, clinical FSD trials are rare compared to the available burgeoning data on men. Furthermore, the amount of data related to the effect of treatment agents used for OAB on the sexual function of women is insufficient in the literature while study comparisons should be made with caution because of differences in study designs and population.

The use of anticholinergics as a first-line treatment for $\mathrm{OAB}$ is well documented. However, many large trials exclude sexual function change assessment after their administration. Tolterodine and oxybutynin are two anticholinergic medications with high quality evidence supporting improvement in sexual function with use. According to Hajebrahimi et al. [7], tolterodine IR significantly improved all domains of sexual function of women with OAB. The FSD was evaluated with the Arizona Sexual Experience Scale (ASEX), a five-topic questionnaire. Rogers et al. [25] evaluated the effect of short term treatment with tolterodine ER on FSD using the Pelvic Organ Prolapse/Urinary Incontinence Sexual Function Questionnaire (PISQ) and Sexual Quality of Life - Female (SQOL-F). OAB symptoms improved with tolterodine ER, as did the scores of sexual health and

Table 4 Comparison of pre-treatment and post-treatment FSFI in Group B

\begin{tabular}{llll}
\hline & Pre-observation & Post-observation & $P$ value \\
\hline Desire & $3.0(1.2)$ & $4.8(1.2)$ & $<0.001$ \\
Arousal & $3.0(0.8)$ & $4.8(0.9)$ & $<0.001$ \\
Lubrication & $3.9(1.1)$ & $4.8(1.2)$ & $<0.001$ \\
Orgasm & $3.6(0.8)$ & $4.8(1.0)$ & $<0.001$ \\
Satisfaction & $3.2(0.8)$ & $4.0(0.8)$ & $<0.001$ \\
Pain & $3.2(0.8)$ & $4.4(1.2)$ & $<0.001$ \\
Total Score of Sexual Function & $20.3(3.8)$ & $26.6(4.2)$ & $<0.001$ \\
\hline
\end{tabular}


Table 5 Correlation between improvements (\%) in lower urinary tract symptoms \& female sexual function

\begin{tabular}{|c|c|c|c|c|c|c|c|c|c|c|c|c|c|c|}
\hline & \multicolumn{2}{|l|}{ Desire } & \multicolumn{2}{|l|}{ Arousal } & \multicolumn{2}{|c|}{ Lubrication } & \multicolumn{2}{|l|}{ Orgasm } & \multicolumn{2}{|c|}{ Satisfaction } & \multicolumn{2}{|l|}{ Pain } & \multicolumn{2}{|c|}{ Total FSFI } \\
\hline & $r_{s}$ & $P$ & $r_{s}$ & $P$ & $r_{s}$ & $P$ & $r_{s}$ & $P$ & $r_{s}$ & $P$ & $r_{s}$ & $P$ & $r_{s}$ & $P$ \\
\hline \multicolumn{15}{|l|}{ Group A } \\
\hline Frequency & -0.088 & 0.553 & 0.220 & 0.298 & -0.201 & 0.171 & -0.237 & 0.104 & 0.015 & 0.918 & -0.105 & 0.479 & -0.254 & 0.081 \\
\hline Urgency & 0.168 & 0.253 & 0.041 & 0.781 & -0.195 & 0.199 & -0.240 & 0.135 & 0.035 & 0.815 & 0.013 & 0.928 & -0.224 & 0.127 \\
\hline Nocturia & 0.209 & 0.154 & 0.157 & 0.286 & -0.188 & 0.201 & 0.062 & 0.674 & 0.240 & 0.101 & -0.054 & 0.714 & 0.181 & 0.219 \\
\hline Incontinence & -0.007 & 0.960 & 0.158 & 0.283 & 0.134 & 0.364 & -0.270 & 0.064 & 0.101 & 0.496 & -0.076 & 0.610 & -0.026 & 0.858 \\
\hline Pads & -0.114 & 0.442 & -0.076 & 0.607 & -0.076 & 0.609 & -0.180 & 0.114 & 0.119 & 0.422 & -0.128 & 0.384 & -0.222 & 0.150 \\
\hline Voided Volume & 0.041 & 0.782 & -0.067 & 0.651 & -0.114 & 0.441 & -0.010 & 0.948 & 0.228 & 0.119 & 0.126 & 0.393 & 0.077 & 0.603 \\
\hline \multicolumn{15}{|l|}{ Group B } \\
\hline Frequency & 0.103 & 0.545 & -0.284 & 0.089 & -0.429 & 0.008 & 0.139 & 0.413 & -0.037 & 0.826 & -0.230 & 0.170 & -0.267 & 0.110 \\
\hline Urgency & 0.005 & 0.977 & -0.002 & 0.991 & 0.163 & 0.335 & -0.119 & 0.484 & 0.253 & 0.132 & 0.011 & 0.946 & 0.008 & 0.638 \\
\hline Nocturia & -0.041 & 0.808 & -0.352 & 0.032 & -0.145 & 0.391 & -0.062 & 0.716 & 0.161 & 0.340 & 0.080 & 0.640 & -0.056 & 0.743 \\
\hline Incontinence & 0.178 & 0.292 & -0.336 & 0.042 & -0.009 & 0.957 & -0.209 & 0.214 & 0.250 & 0.130 & 0.206 & 0.221 & 0.068 & 0.687 \\
\hline Pads & 0.123 & 0.468 & -0.253 & 0.131 & 0.068 & 0.689 & 0.125 & 0.461 & 0.298 & 0.073 & 0.202 & 0.230 & 0.156 & 0.357 \\
\hline Voided Volume & 0.186 & 0.271 & -0.170 & 0.314 & -0.074 & 0.663 & 0.269 & 0.108 & 0.205 & 0.223 & 0.161 & 0.340 & 0.177 & 0.294 \\
\hline
\end{tabular}

anxiety measures in sexually active women with OAB. Rogers et al. [26] revealed that in a population of racially diverse, sexually active women, long term tolterodine ER treatment for $\mathrm{OAB}$ resulted in a relief of symptoms as ascertained in bladder diaries. Their study also validated improved sexual health. Using three items from the King's Health Questionnaire and one item from the Beck Depression Inventory, Sand et al. [27] showed that transdermal oxybutynin treatment for OAB improved sexual function. Young et al. [28], in a prospective study using the FSFI questionnaire, demonstrated that OAB symptom management using solifenacin had a positive outcome on female sexual function, especially on the domains of arousal, desire and satisfaction. On the other hand, according to Jha [29] treatment of OAB symptoms with anticholinergics, in female patients evaluated with the PISQ questionnaire, does not guarantee improvement in sexual health. The small sample size and the uncontrolled design of the studies may not permit the

Table 6 Multivariate linear regression analysis model

\begin{tabular}{lllllll}
\hline Variable & $\mathrm{B}$ & $\mathrm{SE} \mathrm{B}$ & $\beta$ & $P$ value & $95.0 \% \mathrm{Cl}$ & \\
\hline Constant & 1.162 & 0.752 & & 0.126 & -0.336 & 2.660 \\
Group & 24.193 & 3.688 & 0.741 & $<0.001$ & 16.849 & 31.538 \\
Frequency & -0.155 & 0.079 & -0.107 & 0.050 & -0.312 & -0.001 \\
Urgency & 0.003 & 0.049 & 0.005 & 0.951 & -0.095 & 0.101 \\
Nocturia & -0.001 & 0.012 & -0.003 & 0.931 & -0.025 & 0.023 \\
Incontinence & 0.004 & 0.018 & 0.009 & 0.843 & -0.032 & 0.039 \\
Number of pads & -0.015 & 0.031 & -0.036 & 0.629 & -0.077 & 0.047 \\
Voided volume & 0.113 & 0.065 & 0.123 & 0.086 & -0.016 & 0.243 \\
\hline
\end{tabular}

demonstration of a causal relationship between the regimen used for OAB treatment and FSD.

Other factors can have a greater effect on sexual life than urinary incontinence associated with intercourse. However, the enjoyment of intercourse can be adversely effected by urgency and frequency issues, along with the fear of leakage during stimulation and intercourse [30]. After 3 months of mirabegron treatment, results indicated statistically significant improvements in sexual function. These improvements may have played a critical role in overall women's sexual health wellness, as revealed by total FSFI scores and individual sexual domain scores, in Group B. Thus, the improvement of FSFI scores, in the current study, may at least partly be attributable to the established improvements in urgency and frequency.

Numerous studies have demonstrated that sexual function is negatively affected in women with bladder dysfunction [6, 30]. It is obvious that the improvement in lower urinary tract symptoms results in improvement of women's sexual life [7, 25-28]. These previous studies are consistent with our findings, demonstrating a positive influence of OAB symptom treatment with mirabegron on sexual health and quality of life. The fact that the number of incontinence pads used by patients was significantly reduced after treatment, might help women feel more desirable and willing to experience sexual relationships and may represent another mechanism to explain the improvement of FSFI demonstrated in the current study after mirabegron administration.

Extensive data exists on the $\beta_{3}$-adrenergic receptor subtype of the sympathetic nervous system [31, 32]. In a recent study, $\beta_{3}$-receptor stimulation caused rat aorta vasorelaxation via the activation of NO synthase and 
the associated increase of tissue levels of cGMP [33]. Gur et al. [34] demonstrated that mirabegron markedly relaxed isolated human corpus cavernosum (HCC) and rat corpora cavernosa by activating $\beta_{3}$-adrenoceptors independently of the NO-cGMP pathway. Moreover, Cirino et al. [35] showed that the activation of the $\beta_{3}$-receptors present in human corpus cavernosum elicits a cGMP dependent but NO-independent vasorelaxation which involves the inhibition of the RhoA/ Rho-kinase pathway and facilitates erectile function.

An up-regulation of Rho kinase- $\beta$ protein in alloxaninduced diabetic rabbit corporal tissue [36] and in the human corpus cavernosum [37] has recently been shown to control corporal smooth muscle contraction induced by endothelin-1. This suggests that the RhoA/Rho kinase pathway plays a mediatory role in increased sensitivity and force generation of corporal smooth muscle. Additionally, $\beta 3$ receptor-mediated corporal smooth muscle relaxation involves the inhibition of RhoA/Rho-kinase [35]. Smooth muscle relaxation associated with phosphorylation and the resulting inhibition of RhoA is caused by the NO-cGMP signaling pathway mediated by the activation of the cGMP-dependent protein kinase $[35,38,39]$. As the cGMP-dependent protein kinase is found in human corpora cavernosa, this second mechanism is likely to occur in humans too. It seems, therefore,

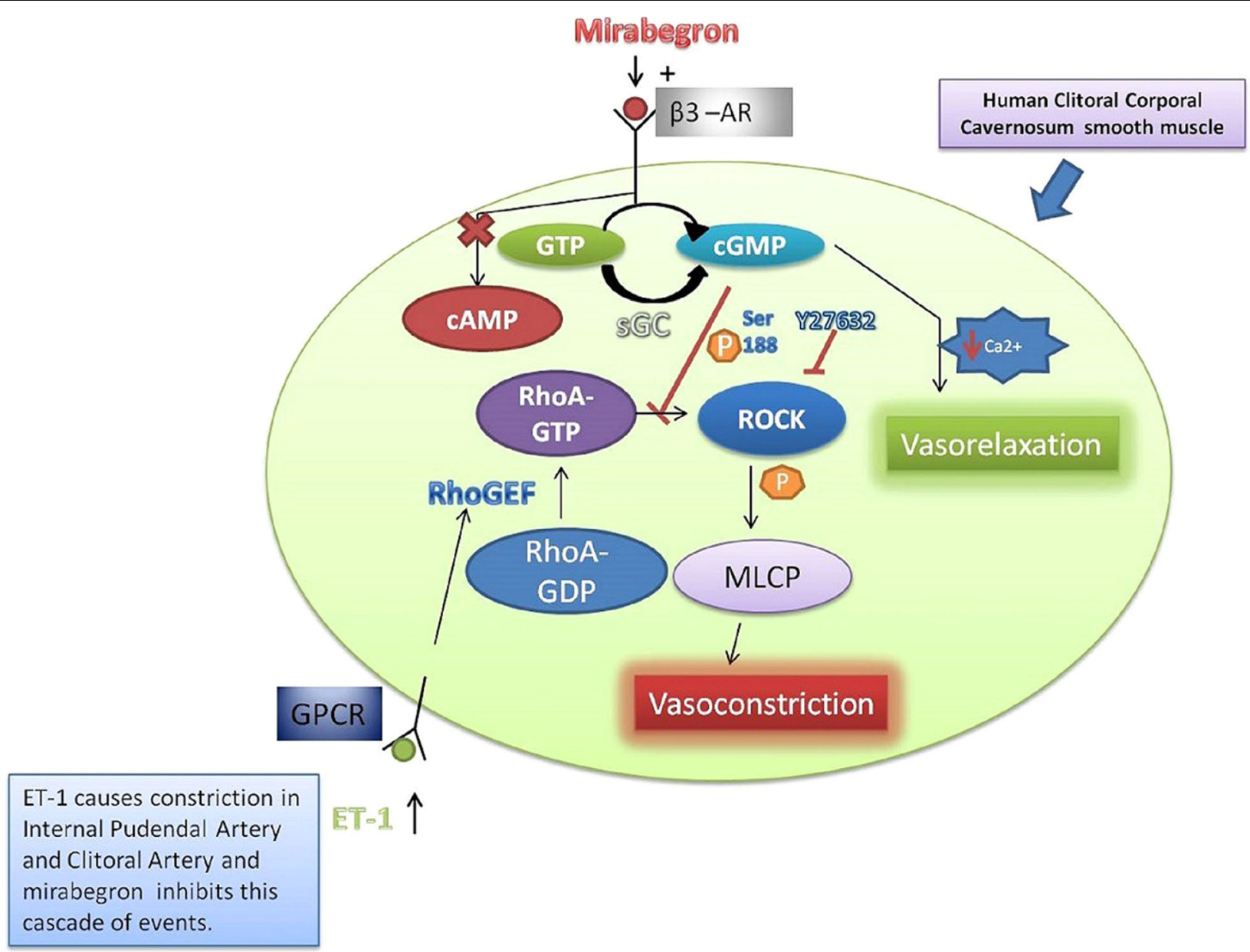

Fig. 1 Possible mechanism of mirabegron's effect, used for overactive bladder treatment, on female sexual function. $\beta 3$ - adrenergic receptor activation by mirabegron agonist is coupled to the generation of the second messenger CGMP, which causes human corporal cavernosum smooth muscle relaxation by lowering intracellular levels of free calcium. $\beta 3$ receptor-mediated corporal smooth muscle relaxation involves inhibition of RhoA/Rho-kinase [34]. The Rho pathway is initiated by ET-1 agonist binding in the GPCR receptor, which activates RhoGEF, facilitating RhoA-GDP conversion to RhoA-GTP. RhoAGTP binds to ROCK, facilitating autophosphorylation of ROCK that enhances its ability to phosphorylate and deactivate MLCP, promoting vasoconstriction. Relaxation is largely mediated by cGMP, which causes phosphorylation of RhoA, preventing interaction with ROCK and thereby inhibiting vasoconstriction. Endothelin-1-induced contraction of corporal smooth is mediated by an up-regulation of Rho kinase- $\beta$ protein in alloxan-induced diabetic human corpus cavernosum [36]. Internal pudendal artery and clitoral artery are sensitive to the potent vasoconstrictor peptide, endothelin-1 (ET-1). The inhibition of Rho-kinase in the internal pudendal artery and clitoral artery reduces ET-1-mediated constriction [39].m. Abr. cGMP: cyclic GMP, GPCR: G-protein-coupled receptor, MLCP: myosin light chain phosphatase, RhoGEF: Rho guanine exchange factor, ROCK: Rho-associated protein kinase, sGC: soluble guanylyl cyclase, Y-27632: (R)-(+)-trans-N-(4-pyridyl)-4-(1-aminoethyl)-cyclohexanecarboxamide, ET-1: Endothelin-1 
that the state of human corpus cavernosum tumescence may be regulated by the physiological function of these two pathways.

The clitoris is a complex structure that simulates the structure of penis, which is composed of two erectile bodies known as the corpora cavernosa. During sexual arousal, both the clitoris and the labia minora become engorged with blood. In addition, both vaginal and clitoral length and diameter increase. To date, the vascular contributions in FSD remain to be elucidated. The main blood supply to female genital tissue is via the internal pudendal artery (IPA) and clitoral artery (CA). A better understanding of female sexual arousal would be made possible if more was known about both these arteries. Allahdadi et al. [40] demonstrated that internal pudendal artery and clitoral artery are sensitive to the potent vasoconstrictor peptide, endothelin-1. Rho-kinase, however is a key component in endothelin-1 signaling. Furthermore, the inhibition of Rho-kinase in the internal pudendal artery and clitoral artery reduces ET-1-mediated constriction [40].

We may hypothesize that mirabegron, as a $\beta_{3}$-adrenoreceptor agonist, induces relaxation of the corpus cavernosum that may enhance blood flow in the female region-clitoris which might be accompanied by increased stimulation. This proposed mechanism of mirabegron explains our results, in which mirabegron treatment caused statistically significant improvements in arousal, desire, orgasm and satisfaction female sexual function domains, as well as in total FSFI score (Fig. 1).

However, the present study has some limitations. Our study had a control group with women not taking mirabegron treatment but there is no placebo group. Thus, there is no evaluation about the effect of placebo on sexual function. It was not possible to use a randomization method since the decision of female patients to receive mirabegron or not, was the reason for being in certain group. Someone could claim that it is a random process of selection although that can by chance lead to disparities. In spite of these limitations, significant results have been obtained, which are of value for clinicians working in this field.

\section{Conclusions}

Females with $O A B$ should be assessed for their sexual function to provide better quality of life. According to the aforementioned data, $\mathrm{OAB}$ treatment with mirabegron improves female sexual function. The above documented improvement in female sexual function might be due to the improvement in the consequences of $\mathrm{OAB}$ pathophysiology. However an alternative mechanism may be raised attributing these beneficial effects in the women who received mirabegron treatment to mirabegron action per se. Our study is adherent to CONSORT guidelines.

\section{Abbreviations}

ASEX: Arizona Sexual Experience Scale; BDI: Beck depression inventory; CA: Clitoral artery; CGMP: Cyclic Guanosine Monophosphate; ET-1: Endothelin-1; FSD: Female sexual dysfunction; FSFI: Female sexual function index; FSFIGr: Female sexual function index -greek; HCC: Human corpus cavernosum; ICS: International Continence Society; IPA: Internal pudendal artery; KHQ: King's Health Questionnaire; NO: Nitric oxide; OAB: Overactive bladder; PISQ: Pelvic Organ Prolapse/Urinary Incontinence Sexual Function Questionnaire; SPSS: Statistical Package for the Social Sciences; SQOL-F: Sexual quality of life female; Tolterodine ER: Tolterodine extended release; Tolterodine IR: Tolterodine immediate release

\section{Acknowledgements}

The authors would like to thank Mrs. D. Pantartzi, Scientific Secretary of the Clinical Trial Office, Department of Urology, University of Crete Medical School for the administrative and technical support.

Funding

ELPIS HOSPITAL.

\section{Availability of data and materials}

The data of the current study are available from the corresponding author on reasonable request.

\section{Authors' contributions}

ZA contributed to conception and design, collected data, contributed to the analysis and interpretation of data, drafted the manuscript and revised it critically for important intellectual content. CM led the analysis, made substantial contribution to the interpretation of data, has been involved in drafting the manuscript and revising it critically for important intellectual content. FM contributed to conception and design, collected data, contributed to the analysis and interpretation of data, drafted the manuscript and revised it critically for important intellectual content. DF, FJ, SS contributed to collection of data, contributed to the analysis and interpretation of data. TP, TA, SN contributed to conception and design, analysis and interpretation of data and helped revise the manuscript critically for important intellectual content. All authors read, approved and agree to be accountable for the final manuscript.

\section{Ethics approval and consent to participate}

The study was approved by ELPIS HOSPITAL Ethics Committee 01/2016. Written informed consent was obtained from all study participants prior to commencement of the study.

Consent for publication

Not applicable.

Competing interests

The authors declare that they have no competing interests.

\section{Publisher's Note}

Springer Nature remains neutral with regard to jurisdictional claims in published maps and institutional affiliations.

\section{Author details}

${ }^{1}$ Department of Urology, School of Medicine, Ioannina University, Ioannina, Greece. ${ }^{2}$ Department of Urology, University General Hospital of Heraklion, University of Crete, Medical School, Heraklion, Greece. ${ }^{3}$ Department of Urology, ELPIS Hospital, Volos, Greece. ${ }^{4}$ Department of Urology, School of Medicine, Tottori University, Yonago, Japan. ${ }^{5} 3$ Spyridi Street, 38221 Volos, Greece.

Received: 11 July 2017 Accepted: 20 June 2018

Published online: 25 June 2018

\section{References}

1. Abrams P, Cardozo L, Fall M, Griffiths D, Rosier P, Ulmsten U, Van Kerrebroeck P, Victor A, Wein A, Standardisation sSub-Committee of the International Continence $\mathrm{S}$. The standardisation of terminology in lower urinary tract function: report from the standardisation sub-committee of the International Continence Society. Urology. 2003;61(1):37-49. 
2. Stewart WF, Van Rooyen JB, Cundiff GW, Abrams P, Herzog AR, Corey R, Hunt TL, Wein AJ. Prevalence and burden of overactive bladder in the United States. World J Urol. 2003;20(6):327-36.

3. Coyne KS, Sexton CC, Thompson CL, Milsom I, Irwin D, Kopp ZS, Chapple CR, Kaplan S, Tubaro A, Aiyer LP, et al. The prevalence of lower urinary tract symptoms (LUTS) in the USA, the UK and Sweden: results from the epidemiology of LUTS (EpiLUTS) study. BJU Int. 2009;104(3):352-60.

4. Coyne KS, Sexton CC, Irwin DE, Kopp ZS, Kelleher CJ, Milsom I. The impact of overactive bladder, incontinence and other lower urinary tract symptoms on quality of life, work productivity, sexuality and emotional well-being in men and women: results from the EPIC study. BJU Int. 2008;101(11):1388-95.

5. Cohen BL, Barboglio P, Gousse A. The impact of lower urinary tract symptoms and urinary incontinence on female sexual dysfunction using a validated instrument. J Sex Med. 2008;5(6):1418-23.

6. Patel AS, O'Leary ML, Stein RJ, Leng WW, Chancellor MB, Patel SG, BorelloFrance $D$. The relationship between overactive bladder and sexual activity in women. Int Braz J Urol. 2006:32(1):77-87.

7. Hajebrahimi S, Azaripour A, Sadeghi-Bazargani H. Tolterodine immediate release improves sexual function in women with overactive bladder. J Sex Med. 2008;5(12):2880-5.

8. Kim YH, Seo JT, Yoon $\mathrm{H}$. The effect of overactive bladder syndrome on the sexual quality of life in Korean young and middle aged women. Int J Impot Res. 2005;17(2):158-63.

9. Zahariou A, Karamouti M, Tyligada E, Papaioannou P. Sexual function in women with overactive bladder. Female Pelvic Med Reconstr Surg. 2010; 16(1):31-6.

10. Laumann EO, Paik A, Rosen RC. Sexual dysfunction in the United States: prevalence and predictors. JAMA. 1999;281(6):537-44.

11. Hayes RD, Dennerstein L, Bennett CM, Fairley CK. What is the "true" prevalence of female sexual dysfunctions and does the way we assess these conditions have an impact? J Sex Med. 2008;5(4):777-87.

12. Rosen R, Brown C, Heiman J, Leiblum S, Meston C, Shabsigh R, Ferguson D, D'Agostino R Jr. The Female Sexual Function Index (FSFI): a multidimensional self-report instrument for the assessment of female sexual function. J Sex Marital Ther. 2000;26(2):191-208.

13. Yamaguchi O. Beta3-adrenoceptors in human detrusor muscle. Urology. 2002;59(5 Suppl 1):25-9.

14. Nitti WW, Auerbach S, Martin N, Calhoun A, Lee M, Herschorn S. Results of a randomized phase III trial of mirabegron in patients with overactive bladder. J Urol. 2013;189(4):1388-95.

15. Khullar V, Amarenco G, Angulo JC, Cambronero J, Hoye K, Milsom I, Radziszewski P, Rechberger T, Boerrigter P, Drogendijk T, et al. Efficacy and tolerability of mirabegron, a beta(3)-adrenoceptor agonist, in patients with overactive bladder: results from a randomised European-Australian phase 3 trial. Eur Urol. 2013;63(2):283-95.

16. Herschorn S, Barkin J, Castro-Diaz D, Frankel JM, Espuna-Pons M, Gousse AE, Stolzel M, Martin N, Gunther A, Van Kerrebroeck P. A phase III, randomized, double-blind, parallel-group, placebo-controlled, multicentre study to assess the efficacy and safety of the beta(3) adrenoceptor agonist, mirabegron, in patients with symptoms of overactive bladder. Urology. 2013;82(2):313-20.

17. Yamaguchi $O$, Marui $E$, Kakizaki H, Homma $Y$, Igawa $Y$, Takeda M, Nishizawa O, Gotoh M, Yoshida M, Yokoyama O, et al. Phase III, randomised, doubleblind, placebo-controlled study of the beta3-adrenoceptor agonist mirabegron, $50 \mathrm{mg}$ once daily, in Japanese patients with overactive bladder. BJU Int. 2014;113(6):951-60.

18. Nitti WW, Khullar V, van Kerrebroeck P, Herschorn S, Cambronero J, Angulo JC, Blauwet MB, Dorrepaal C, Siddiqui E, Martin NE. Mirabegron for the treatment of overactive bladder: a prespecified pooled efficacy analysis and pooled safety analysis of three randomised, double-blind, placebocontrolled, phase III studies. Int J Clin Pract. 2013;67(7):619-32.

19. Chapple CR, Kaplan SA, Mitcheson D, Klecka J, Cummings J, Drogendijk T, Dorrepaal C, Martin N. Randomized double-blind, active-controlled phase 3 study to assess 12-month safety and efficacy of mirabegron, a beta(3)adrenoceptor agonist, in overactive bladder. Eur Urol. 2013;63(2):296-305.

20. Zahariou AG, Karamouti MV, Papaioannou PD. Pelvic floor muscle training improves sexual function of women with stress urinary incontinence. Int Urogynecol J Pelvic Floor Dysfunct. 2008;19(3):401-6.

21. Hatzichristou D, Kirana PS, Banner L, Althof SE, Lonnee-Hoffmann RA, Dennerstein L, Rosen RC. Diagnosing sexual dysfunction in men and women: sexual history taking and the role of symptom scales and questionnaires. J Sex Med. 2016;13(8):1166-82.
22. Zachariou A, Filiponi M, Kirana PS. Translation and validation of the Greek version of the female sexual function index questionnaire. Int J Impot Res. 2017;29(4):171-4.

23. Wiegel M, Meston C, Rosen R. The female sexual function index (FSFI): cross-validation and development of clinical cutoff scores. J Sex Marital Ther. 2005;31(1):1-20.

24. Chedraui P, Perez-Lopez FR, San Miguel G, Avila C. Assessment of sexuality among middle-aged women using the Female Sexual Function Index. Climacteric. 2009;12(3):213-21.

25. Rogers R, Bachmann G, Jumadilova Z, Sun F, Morrow JD, Guan Z, Bavendam T. Efficacy of tolterodine on overactive bladder symptoms and sexual and emotional quality of life in sexually active women. Int Urogynecol J Pelvic Floor Dysfunct. 2008;19(11):1551-7.

26. Rogers RG, Omotosho T, Bachmann G, Sun F, Morrow JD. Continued symptom improvement in sexually active women with overactive bladder and urgency urinary incontinence treated with tolterodine ER for 6 months. Int Urogynecol J Pelvic Floor Dysfunct. 2009;20(4):381-5.

27. Sand PK, Goldberg RP, Dmochowski RR, Mcllwain M, Dahl NV. The impact of the overactive bladder syndrome on sexual function: a preliminary report from the Multicenter Assessment of Transdermal Therapy in Overactive Bladder with Oxybutynin trial. Am J Obstet Gynecol. 2006;195(6):1730-5.

28. Young O, Hyo K, Won H, Jin B, Changhee Y, Goo L, Seon C. Clinical efficacy of solifenacin on female sexual dysfunction in patients with overactive bladder (SOS trial; Solifenacin on Overactive bladder and Sexual dysfunction). J Urol. 2013;189:e618-9.

29. Jha S. Impact of treatment of overactive bladder with anticholinergics on sexual function. Arch Gynecol Obstet. 2016;293(2):403-6.

30. Coyne KS, Margolis MK, Jumadilova Z, Bavendam T, Mueller E, Rogers R. Overactive bladder and women's sexual health: what is the impact? I Sex Med. 2007:4(3):656-66.

31. Strosberg AD. Structure and function of the beta 3-adrenergic receptor. Annu Rev Pharmacol Toxicol. 1997;37:421-50.

32. Guimaraes S, Moura D. Vascular adrenoceptors: an update. Pharmacol Rev. 2001;53(2):319-56.

33. Trochu JN, Leblais $\vee$, Rautureau Y, Beverelli F, Le Marec H, Berdeaux A, Gauthier C. Beta 3-adrenoceptor stimulation induces vasorelaxation mediated essentially by endothelium-derived nitric oxide in rat thoracic aorta. Br J Pharmacol. 1999;128(1):69-76.

34. Gur S, Peak T, Yafi FA, Kadowitz PJ, Sikka SC, Hellstrom WJ. Mirabegron causes relaxation of human and rat corpus cavernosum: could it be a potential therapy for erectile dysfunction? BJU Int. 2016;118(3):464-74.

35. Cirino G, Sorrentino $R$, di Villa Bianca R, Popolo A, Palmieri A, Imbimbo C, Fusco F, Longo N, Tajana G, Ignarro LJ, et al. Involvement of beta 3-adrenergic receptor activation via cyclic GMP- but not NO-dependent mechanisms in human corpus cavernosum function. Proc Natl Acad Sci U S A. 2003;100(9):5531-6.

36. Chang S, Hypolite JA, Changolkar A, Wein AJ, Chacko S, DiSanto ME. Increased contractility of diabetic rabbit corpora smooth muscle in response to endothelin is mediated via Rho-kinase beta. Int J Impot Res. 2003;15(1):53-62.

37. Wang H, Eto M, Steers WD, Somlyo AP, Somlyo AV. RhoA-mediated Ca2+ sensitization in erectile function. J Biol Chem. 2002;277(34):30614-21.

38. Sawada N, Itoh H, Yamashita J, Doi K, Inoue M, Masatsugu K, Fukunaga Y, Sakaguchi S, Sone M, Yamahara K, et al. cGMP-dependent protein kinase phosphorylates and inactivates RhoA. Biochem Biophys Res Commun. 2001;280(3):798-805.

39. Sauzeau V, Le Jeune H, Cario-Toumaniantz C, Smolenski A, Lohmann SM, Bertoglio J, Chardin P, Pacaud P, Loirand G. Cyclic GMP-dependent protein kinase signaling pathway inhibits RhoA-induced Ca2+ sensitization of contraction in vascular smooth muscle. J Biol Chem. 2000;275(28):21722-9.

40. Allahdadi KJ, Hannan JL, Tostes RC, Webb RC. Endothelin-1 induces contraction of female rat internal pudendal and clitoral arteries through ET(A) receptor and rho-kinase activation. J Sex Med. 2010;7(6):2096-103. 